\title{
Modeling of Simultaneous Oxidation and Volatilization Phenomena along a Crack in a Self-healing Multi- constituent Material
}

\author{
Coraline Simon $^{\mathrm{a}, \mathrm{b}}$, Gérald Camus ${ }^{\mathrm{a}}$, Florent Bouillon ${ }^{\mathrm{b}}$, Francis Rebillat $^{\mathrm{a}}$ \\ ${ }^{a}$ Laboratoire des Composites Thermostructuraux, (Université de Bordeaux-CNRS-CEA-SAFRAN), 3 allée de la \\ Boétie, 33600 Pessac, France \\ ${ }^{b}$ SAFRAN Ceramics, Rue de Touban - Les 5 Chemins, 33185 Le Haillan, France
}

simon@lcts.u-bordeaux.fr; camus@lcts.u-bordeaux.fr; florent.bouillon@safrangroup.com; rebillat@lcts.ubordeaux.fr

\begin{abstract}
Multi-layer Ceramic Matrix Composites with self-healing capacities have been developed for hightemperature aeronautical applications. However, the use of these sophisticated materials lead to complex thermochemical behavior which requires a proper analysis. Previous models have allowed to determine the quantity of oxygen reaching the fiber at the end of a crack, in a dry atmosphere. The focus of this study was to extend this model to the case of humid atmospheres, for the presence of moisture can lead to the volatilization of the healing oxide. Applications of the model have been performed on a material composed of successive layers of $\mathrm{SiC}$ and $\mathrm{B}_{4} \mathrm{C}$. Changes of the crack wall surface could then be evaluated, as well as the healing or recession behavior, and the evolution of the oxygen concentration. Moreover, the introduction of a uniform equivalent averaged material allowed estimations of the consumption of all constituents, and in particular of carbon interphase, over durations representative of aeronautical service lives.
\end{abstract}

Keywords: Oxidation, modeling, self-healing matrix, volatilization

\section{INTRODUCTION}

Ceramic matrix composites such as $\mathrm{SiC} / \mathrm{SiC}$ can be sensitive to oxidation in environments representative of aeronautical engine conditions. When oxygen reaches the interphase surrounding fibers through micro-cracks generated paths, this interphase can then be consumed by oxidation (above $400^{\circ} \mathrm{C}$ for pyrocarbon, which is the interphase of the composite considered in this study), which contributes to strongly reduce the mechanical properties of the material. That is the reason why self-healing composites based on a Si-B-C matrix have been developed, allowing healing of the cracks through the onset of an oxide glassy phase. However, this oxide tends to volatilize in the presence of moisture, which increases the duration required for healing and can even lead to a recession of the crack walls (thus completely impeding healing).

Various models have been proposed in order to evaluate the quantity of consumed interphase in a given environment: they respectively describe (i) a single crack surrounding a fiber [1,3], (ii) a crack orthogonal to the fiber [2], and (iii) a combination of those two approaches [4-6]. The effect of oxidation on the creep behavior has also been estimated through the introduction of a delay factor in the evolution of the quantity of consumed interphase [7]. All these models have been developed for less complex matrix architectures and/or for a dry 
atmosphere, since they do not consider the volatilization of the oxide (except [3]). The introduction of the effects of humidity in a multi-constituent material, which can lead to the volatilization of the healing oxide, is therefore the focus of the present study.

The aim of this work is to build up a model representative of a crack network in multi-constituent materials, which can provide, in given environment conditions (including humidity), the evolution of the crack wall profile, the time required for healing, the evolution of the oxygen concentration profile inside the crack and the quantity of oxygen reaching the front line of this crack. Moreover, in order to take into account more complex geometries and larger scales closer to real parts, the introduction of an averaged material is proposed. The crack is then considered to be present in a uniform equivalent material displaying a behavior similar to that of the multi-constituent material. Hence the mesh of the FEM numerical method used in the model requires less refinement to provide results for larger scale geometries and longer time durations.

This method could be extended to other systems of complex architecture involving different constituents.

\section{MODEL DESCRIPTION}

The model is hereafter described in three steps. The main elements of the oxidation model in a dry atmosphere described in [6] are firstly summed up. In a second part, the introduction of the phenomenon of oxide volatilization is presented. Finally, the design of an equivalent averaged material is exposed.

\section{Oxidation in Dry Atmosphere}

The specific composition of the material can be easily introduced in the model. As an example, the case of a matrix composed of 5 successive layers of two constituents ( $\mathrm{SiC}$ and $\mathrm{B}_{4} \mathrm{C}$, cf. Fig. 1), SiC Nicalon fibers, and a pyrocarbon interphase is considered. Environment conditions and the geometry of the crack are given as inputs.

In the presence of oxygen, the oxidation of $\mathrm{SiC}$ and $\mathrm{B}_{4} \mathrm{C}$ leads to the formation of condensed phases (respectively $\mathrm{SiO}_{2}$ and $\mathrm{B}_{2} \mathrm{O}_{3}$ ) and the release of gas such as $\mathrm{CO}$ or $\mathrm{CO}_{2}$.

For each time step, the local quantity of oxygen consumed by the crack walls (depending on the local constituent) is calculated, taking into account the Fick and Knudsen regimes. The thickness of the oxide layer due to the oxidation of the local matrix constituent is also calculated.

These data are provided by the resolution of the following non-linear differential equation [1,2] through GaussNewton iterations and a finite element method approach:

$$
\frac{d}{d z}\left[\frac{-D_{e f f}(z) e(z)}{1-\left(1-n_{g a s} / n_{O_{2}}\right) X_{0}} \frac{d C(z)}{d z}\right]+\frac{n_{O_{2}}}{n_{o x}} \frac{\rho_{o x}}{M_{o x}} \frac{K_{p i}}{\delta(z)}\left(\frac{C(z)}{C_{r}}\right)^{N p}=0
$$

where all symbols are described in the list of variables at the end of the paper.

The boundary condition at the crack front is provided by the consumption of oxygen by the carbon interphase, and is similar to the one proposed by Filipuzzi [1].

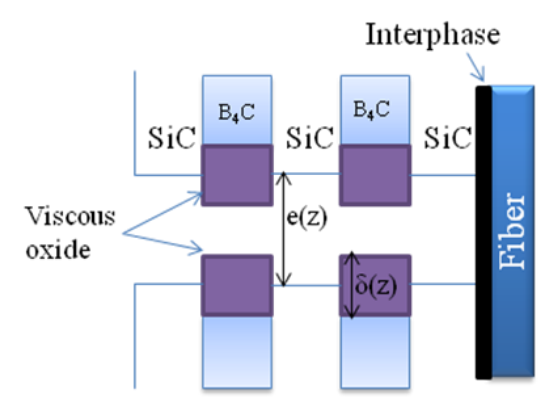

FIGURE 1. Spreading at regular time intervals of the viscous oxide along the surfaces of the crack 
The local thickness of this oxide is given by a parabolic law until the crack may be considered as being sealed by an oxide "cork" [8]. In the case of the considered material, the oxide $\mathrm{B}_{2} \mathrm{O}_{3}$ is formed much quicker than $\mathrm{SiO}_{2}$ due to its higher parabolic rate constant. Above $450^{\circ} \mathrm{C}, \mathrm{B}_{2} \mathrm{O}_{3}$ is in a liquid state and tends therefore to spread along the crack walls. This behavior is introduced by periodically reporting the oxide layer contributing to the sealing (above the initial crack surface) as a uniform layer all over the crack wall, as depicted in Fig. 1. The consequent oxide thickness $\delta(z)$ is then introduced in Eq.1 at the next time step.

When the crack is completely sealed with oxide, the diffusion of oxygen then can only occur within this oxide in a liquid state, leading to a dramatic decrease of its diffusion coefficient. The program keeps calculating the evolution of the oxygen profile after crack healing, and can therefore estimate the time for the oxygen to diffuse within the oxide over all the crack depth and to oxidize again the interphase.

\section{Introduction of Volatilization in the Presence of Moisture}

The healing oxide can volatilize in the presence of moisture: for instance, $\mathrm{B}_{2} \mathrm{O}_{3}$ will react with $\mathrm{H}_{2} \mathrm{O}$ to form gaseous species such as $\mathrm{H}_{3} \mathrm{BO}_{3}, \mathrm{H}_{3} \mathrm{~B}_{3} \mathrm{O}_{6}$ and $\mathrm{HBO}_{2}$ (later referred to as $\mathrm{HxByOz}$ ). The partial pressure $P_{i}$ of each of these species is linked to the water pressure by its corresponding activation energy $E a_{i}$, partial order $N_{i}$, and linear rate constant $K_{i}$. The total pressure of $\mathrm{HxByOz}$ species is the sum of each partial pressure $P_{i}$ weighted by $n_{i}$, the quantity of $\mathrm{B}_{2} \mathrm{O}_{3}$ in each mole of the gaseous species:

$$
P_{H x B y O z}=\sum_{i=1}^{3} n_{i} P_{i}=\sum_{i=1}^{3} n_{i} K_{i} \exp \left(-E a_{i} / R T\right) P\left(H_{2} O\right)^{N i}
$$

In the considered situation, the boron content is globally uniform along the crack, from the entrance to its front, (no punctual source is present as it would be the case with a BN interphase [3]), so that the formation of hydroxide may also be considered as uniform. Thus, the convective flow through the opened section of the crack is much lower than the diffusive flow [9], and the release of $\mathrm{HxByOz}$ out of this crack becomes the limiting step. Therefore, the rate-limiting mechanism is the removal of the gaseous species out of the crack and not the diffusion within the crack. This justifies considering the pressure of $\mathrm{H}_{2} \mathrm{O}$ (and consequently the pressure of $\mathrm{HxByOz}$ species) to be uniform along the crack.

This hypothesis implies that, at each time step, the "thickness" of the volatilized quantity is distributed evenly along the crack. If the local oxide thickness is lower than the thickness which has been calculated as to be volatilized, volatilization is transferred to the places where enough oxide is available, in order to keep the same global volatilized volume during this time step (in a conservative way).

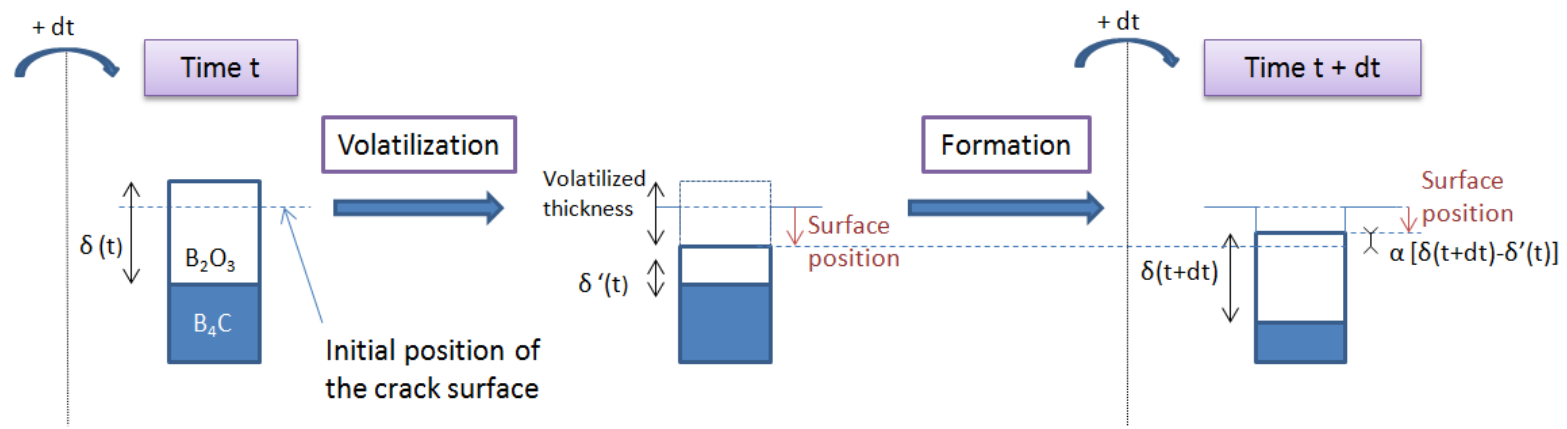

FIGURE 2. Example of evolution of the oxide thickness during an oxide volatilization step and an oxide formation step, in the case of a recession situation

The volatilization speed $\mathrm{V}_{\mathrm{v}}$ of the oxide $\mathrm{B}_{2} \mathrm{O}_{3}$ depends on the maximum width of the crack $e_{0}$, the length of the crack $L f$ (in the y direction in Fig. 1), the speed of the gas in the hot zone $v_{\text {hot gas }}$, the temperature $\mathrm{T}$ and the pressure of HxByOz species $P_{H x B y O z}$ :

$$
V_{v}(\mathrm{~mol} / \mathrm{s})=e_{0} L_{f} v_{\text {hotgas }} \sum P_{H x B y O z} \frac{1}{R T}
$$


At each time step, the local thickness of the generated oxide is calculated, and its possible spreading is taken into account (Fig. 1). The volatilization speed is then calculated, and the corresponding volatilized thickness is subtracted (with possible transfer where oxide is available).

This process is depicted in the case of a single $\mathrm{B}_{4} \mathrm{C}$ layer on Fig. 2: at time step $t$, this layer has given rise to a thickness $\delta(t)$ of oxide. The volatilized thickness is calculated for a duration $d t$ and subtracted, leading to an intermediate oxide thickness $\delta^{\prime}(t)$, and reducing the surface position. In the next time step, the thickness of the generated oxide is calculated: the new position of the oxide surface depends on the generated oxide thickness multiplied by the volumetric expansion coefficient $\alpha$ introduced by oxidation. It can be noted that the amount of $\mathrm{B}_{4} \mathrm{C}$ decreases during this operation, and this particular situation will lead to a recession of the $\mathrm{B}_{4} \mathrm{C}$ layers.

\section{Towards Applications to Complex Geometries: Definition of an Averaged Material}

Solving the model described above requires a FEM mesh with several nodes for each constituent layer in order to be sufficiently accurate. Consequently, it is hardly transposable to much larger parts or durations of a few thousands of hours (as in aeronautical applications). The concept of an averaged material has therefore been developed: this averaged material is uniform, i.e. it does not possess different constituent layers, but it has an oxidation behavior similar to the multi-constituent material. Such a uniform material does not require a refined meshing, and would therefore allow calculations on larger space and time scales.

This averaged material is described by the volumetric fraction of each of its constituent. In the case of a carbon interphase, the estimated volumetric fraction of carbon $X_{\text {carb }}$ is estimated and considered to be evenly distributed within the material (which constitutes a rational hypothesis at the size of a sample). As represented on Fig. 3b, at each $\mathrm{z}$ position in the crack depth, the averaged material is uniform and contains a representative fraction of each constituent (in the plane $(y, z)$ different from the plane $(x, z)$ of Fig. 1). The degree of mixing of all the constituents is considered to have no influence on the local oxidation rate.

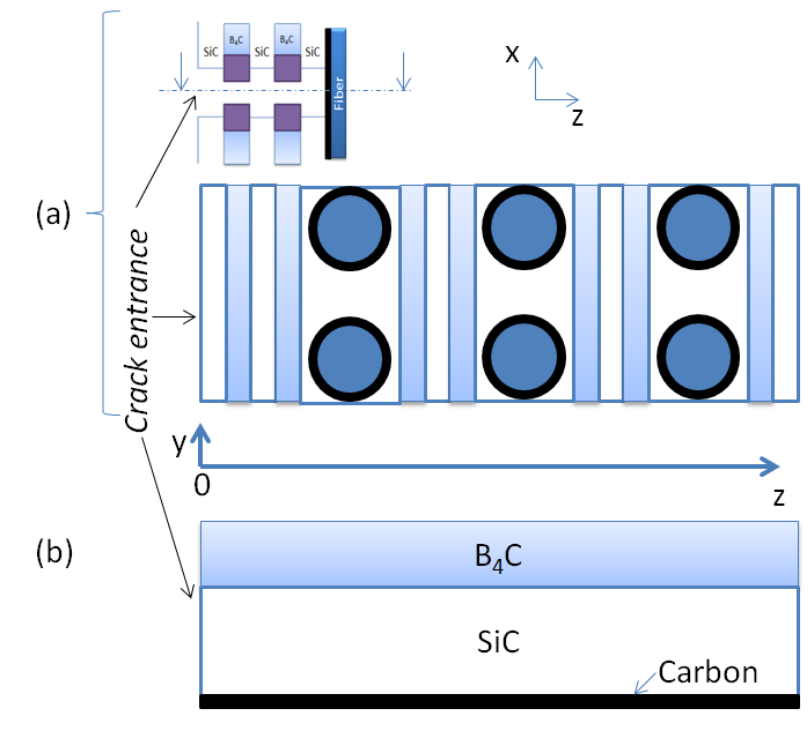

FIGURE 3. Representations of (a) the initial multi-layered material, (b) the averaged material related to (a)

The rate law which rules the thermo-chemical behavior of the material has to be adapted to the averaged version. The differential equation (1) refers to various constituent-dependent parameters which where locally evaluated on each node. For the uniform averaged material, equation (1) is adapted by adding the contribution of each constituent weighted by its volumetric fraction. In the case of a material containing $\mathrm{SiC}, \mathrm{B}_{4} \mathrm{C}$ and a carbon interphase, equation (4) has thus to be considered. 


$$
\begin{aligned}
& \frac{d}{d z}\left[\frac{-D_{e f f}(z) e(z)}{1-\left(1-n_{\text {gas }} / n_{O_{2}}\right) X_{0}} \frac{d C(z)}{d z}\right]+X_{S i C} \frac{n_{O_{2}}}{n_{S_{O} O_{2}}} \frac{\rho_{S_{O_{2}}}}{M_{S i O_{2}}} \frac{K_{p S i C}}{\delta(z)}\left(\frac{C(z)}{C_{r}}\right)^{N p S i C} \\
& +X_{B_{4} C} \frac{n_{O_{2}}}{n_{B_{2} O_{3}}} \frac{\rho_{B_{2} O_{3}}}{M_{B_{2} O_{3}}} \frac{K_{p B_{4} C}}{\delta(z)}\left(\frac{C(z)}{C_{r}}\right)^{N p B_{4} C}+X_{c a r b} K_{C}\left(\frac{C(z)}{C_{r}}\right)^{N c}=0
\end{aligned}
$$

where $K_{c}$ is the linear rate constant for carbon and $N c$ its partial order.

The only space dependant parameters are the oxygen concentration $C(z)$, and the thickness of the oxide layer $\delta(z)$ (which is linked to the crack width $e(z)$ and the diffusion coefficient $D_{e f f}(z)$ ).

As previously explained, the reactivity of $\mathrm{B}_{4} \mathrm{C}$ is much higher than the one of $\mathrm{SiC}$, and $\mathrm{B}_{2} \mathrm{O}_{3}$ is the main oxide contributing to the healing of the crack. Therefore, for more efficiency of this version of the model, it is considered that $\mathrm{B}_{2} \mathrm{O}_{3}$ is the only present oxide. The contribution of $\mathrm{SiC}$ is taken into account to evaluate the oxygen concentration (Eq.4), whereas its involvement in the oxide volume is negligible. At each time, the thickness of the oxide created, $d \delta$ is calculated on the basis of $\mathrm{B}_{4} \mathrm{C}$ volumetric fraction $X_{B 4 C}$ :

$$
d \delta=X_{B_{4} C} K_{p B_{4} C}\left(\frac{C(z)}{C_{r}}\right)^{N p B_{4} C} \frac{1}{2 \beta \delta(z)} d t
$$

A coefficient $\beta$ which depends on the volumetric fractions of $\mathrm{SiC}$ and $\mathrm{B}_{4} \mathrm{C}\left(\beta=1+\mathrm{X}_{\mathrm{SiC}} / \mathrm{X}_{\mathrm{B} 4 \mathrm{C}}\right)$ is introduced in order to consider the higher thickness of oxide provided by $\mathrm{B}_{4} \mathrm{C}$ in the calculation of the created oxide: in the multiconstituent material, the oxide appears preferentially on the $\mathrm{B}_{4} \mathrm{C}$ layers, but if it is considered as being evenly distributed, the $\mathrm{B}_{2} \mathrm{O}_{3}$ local thickness $\delta(\mathrm{z})$ (in regard to $\mathrm{B}_{4} \mathrm{C}$ ) is underestimated and therefore the thickness $d \delta$ is largely overestimated. Apart from this adaptation, all the previously described processes of oxide spreading and volatilization remain unchanged.

The carbon interphase is considered to be evenly distributed within the material with a volumetric fraction $X_{\text {carb }}$. At each time step and for each position $z$, the length of the local consumed interphase is given by:

$$
d l_{C}=X_{c a r b} K_{C}\left(\frac{C(z)}{C_{r}}\right)^{N c} \frac{M_{C}}{\rho_{C}} d t
$$

This allows the evaluation of the profile of consumed interphase along the crack depth as well as of its evolution.

\section{RESULTS AND DISCUSSION}

\section{Application to a Composite with a Matrix composed of 5 Layers in a Wet Atmosphere}

The enhanced model handling volatilization has been applied to a material with a matrix made of five $4 \mu \mathrm{m}$ layers of $\mathrm{SiC}$ and $\mathrm{B}_{4} \mathrm{C}$, presenting a $2 \mu \mathrm{m}$-large crack. The profile of the crack wall surface is depicted on Fig. 4 after 1s and 50s of exposition under $\mathrm{T}=900^{\circ} \mathrm{C}$ and $\mathrm{P}\left(\mathrm{H}_{2} \mathrm{O}\right)=10 \mathrm{kPa}$. As the $\mathrm{SiC}$ layers are much less reactive than $\mathrm{B}_{4} \mathrm{C}$, the $\mathrm{B}_{4} \mathrm{C}$ layers are thus consumed much more rapidly, leading quickly to the non-uniform profile displayed in Fig. 4a. After 1s, a thin layer of oxide is present over the $\mathrm{B}_{4} \mathrm{C}$ layers, and the position of the top of this oxide layer is about $0.4 \mu \mathrm{m}$ under the initial position of the sample surface. After $50 \mathrm{~s}$, the surface of the $\mathrm{B}_{4} \mathrm{C}$ layers is much lower $(-20 \mu \mathrm{m})$ and the oxide is almost no longer present. Indeed, in such strong conditions, all the created oxide is immediately volatilized, leading to the recession of the $\mathrm{B}_{4} \mathrm{C}$ layers. For larger times and in a real material, the formation of borosilicate, more stable, may contribute to a partial limitation of this layer recession [10].

The behavior of the material is different in the case of lower humidity pressures. As a reference, the same calculation has been performed in a dry atmosphere, i.e. with $\mathrm{P}\left(\mathrm{H}_{2} \mathrm{O}\right)$ set up to zero. In such a dry atmosphere, the oxide does not volatilize and the complete healing of the crack occurs. The position of the crack wall is presented in 
Fig. 5a, with oscillations due to the periodic spreading of the liquid oxide. The surface has a parabolic evolution, and reaches $1 \mu \mathrm{m}$ (half of the crack opening, by symmetry) after 102s.

When $\mathrm{P}\left(\mathrm{H}_{2} \mathrm{O}\right)$ is increased, a fraction of the oxide is volatilized, and the time before healing therefore increases. However, when the water pressure reaches $3 \mathrm{kPa}$, a drastic change of behavior occurs: the maximum healing capacity in these conditions is slightly inferior to the semi-crack width (Fig. 5b), and the step of recession of the $\mathrm{B}_{4} \mathrm{C}$ surface is reached (typical parabolic-linear evolution [11]). The crack will therefore no longer be sealed for water pressures above $3 \mathrm{kPa}$ (all other conditions being identical).

This model accurately reproduces the behaviors of recession or healing typical of the competition between oxidation and volatilization. Such evolutions of crack wall surfaces are in good agreement with experimental observations on model linear cracks in real self-healing composites [14].
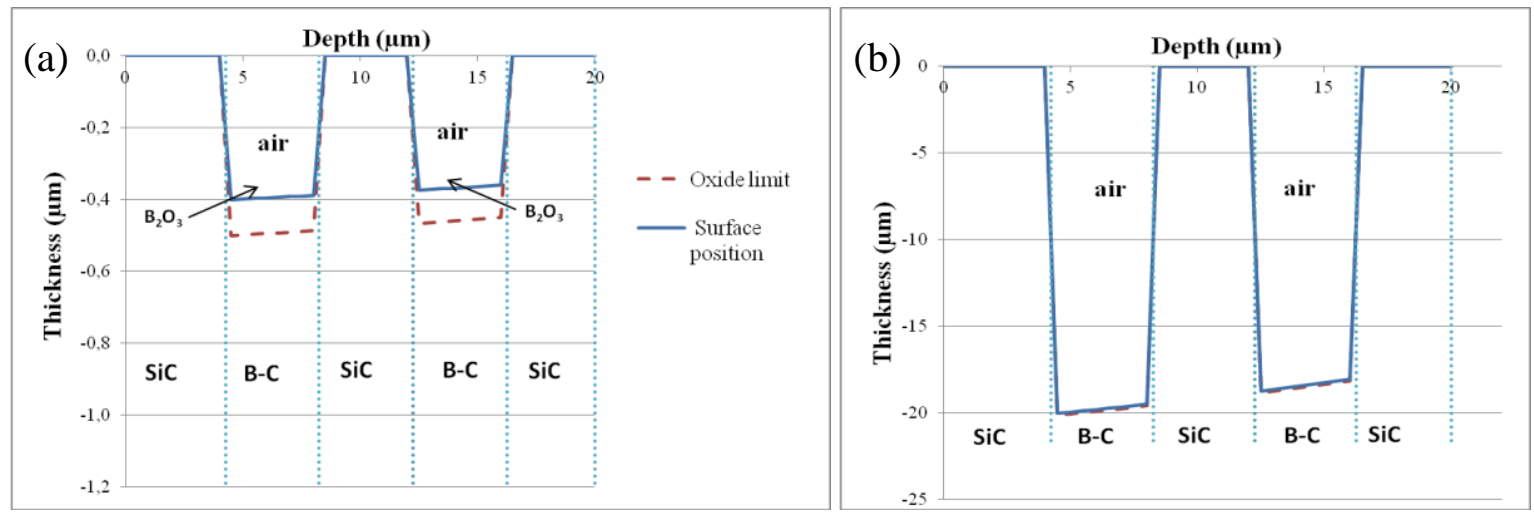

FIGURE 4. Thickness profile of a crack in a 5-layer $\mathrm{CMC}, \mathrm{P}_{\text {tot }}=10^{5} \mathrm{~Pa}, \mathrm{P}\left(\mathrm{O}_{2}\right)=2.10^{4} \mathrm{~Pa}, \mathbf{P}\left(\mathbf{H}_{\mathbf{2}} \mathbf{O}\right)=\mathbf{1 0} \mathbf{~ k P a}, \mathrm{T}=$ $900^{\circ} \mathrm{C}$, gas speed: $1 \mathrm{~m} / \mathrm{s}$ (cold zone), at $(a) \mathrm{t}=1 \mathrm{~s}$ and $(b) \mathrm{t}=50 \mathrm{~s}$
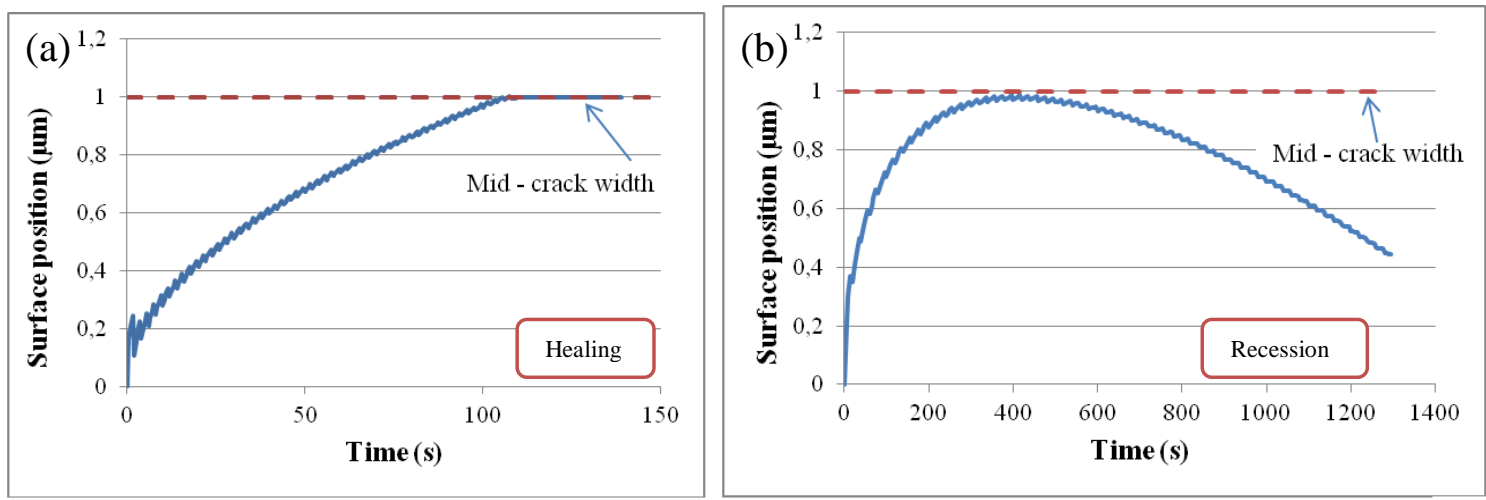

FIGURE 5. Evolution of the position of the crack wall surface in 5-layer $\mathrm{CMC}, \mathrm{P}_{\mathrm{tot}}=10^{5} \mathrm{~Pa}, \mathrm{P}\left(\mathrm{O}_{2}\right)=2.10^{4} \mathrm{~Pa}$, $\mathrm{T}=900^{\circ} \mathrm{C}$, gas speed: $1 \mathrm{~m} / \mathrm{s}$ (cold zone), with $(a) \mathbf{P}\left(\mathbf{H}_{2} \mathbf{O}\right)=\mathbf{0}$ and $(b) \mathbf{P}\left(\mathbf{H}_{2} \mathbf{O}\right)=\mathbf{3} \mathbf{~ k P a}$

\section{Averaged Material}

In order to validate this global approach, the same geometry constituting a so-called reference material was first considered: five 4- $\mu \mathrm{m}$ layers of $\mathrm{SiC}$ and $\mathrm{B}_{4} \mathrm{C}$, and a $2 \mu \mathrm{m}$-crack opening. The averaged material is then composed of the related volumetric fraction of each component: $59.5 \%$ of $\mathrm{SiC}, 39.5 \%$ of $\mathrm{B}_{4} \mathrm{C}$ and $1 \%$ of carbon.

The calculated behaviors of the reference material and of the average material are compared in Table 1, for various pressures of $\mathrm{H}_{2} \mathrm{O}$. It appears that the same type of behavior (healing or recession) is depicted in each situation, and the numeric values of time before healing and surface position are sufficiently close in regard with the performed simplification. 
TABLE 1. Comparison of simulation results with the 5-layer material and the related averaged material, for various levels of $\mathrm{H}_{2} \mathrm{O}$ pressure. Crack length: $20 \mu \mathrm{m}$, crack width: $2 \mu \mathrm{m}, \mathrm{T}=900^{\circ} \mathrm{C}$. For the recession cases, the given surface positions are averaged values on the $\mathrm{B}_{4} \mathrm{C}$ layers.

\begin{tabular}{|c|c|c|c|c|c|}
\hline & $\mathbf{P}\left(\mathbf{H}_{2} \mathbf{O}\right)=\mathbf{0}$ & $\mathrm{P}\left(\mathrm{H}_{2} \mathrm{O}\right)=1 \mathrm{kPa}$ & $\mathbf{P}\left(\mathrm{H}_{2} \mathrm{O}\right)=2 \mathrm{kPa}$ & $\mathbf{P}\left(\mathrm{H}_{2} \mathrm{O}\right)=3 \mathrm{kPa}$ & $\mathrm{P}\left(\mathrm{H}_{2} \mathrm{O}\right)=4 \mathrm{kPa}$ \\
\hline 5-layer & Healing & Healing & Healing & Recession & Recession \\
\hline Material & $110 \mathrm{~s}$ & $260 \mathrm{~s}$ & $354 \mathrm{~s}$ & $\begin{array}{l}\text { Initial Surface } \\
+0.7 \mu \mathrm{m} \text { at } 1000 \mathrm{~s}\end{array}$ & $\begin{array}{l}\text { Initial Surface } \\
-0.7 \mu \mathrm{m} \text { at } 1000 \mathrm{~s}\end{array}$ \\
\hline Averaged & Healing & Healing & Healing & Recession & Recession \\
\hline Material & $179 \mathrm{~s}$ & $235 \mathrm{~s}$ & $424 \mathrm{~s}$ & $\begin{array}{c}\text { Initial Surface } \\
+0.4 \mu \mathrm{m} \text { at } 1000 \mathrm{~s}\end{array}$ & $\begin{array}{l}\text { Initial Surface } \\
-0.4 \mu \mathrm{m} \text { at } 1000 \mathrm{~s}\end{array}$ \\
\hline
\end{tabular}

Once the correspondence between the two models had been evaluated with a small crack (total matrix thickness: $20 \mu \mathrm{m})$ and short times, it then became possible to use the averaged material version on a much deeper crack $(1 \mathrm{~mm}$ matrix thickness, which is closer to its related averaged material than a superficial crack), and for extended time durations (with of course a less refined mesh). The calculations have been performed on this averaged material with $\mathrm{P}\left(\mathrm{H}_{2} \mathrm{O}\right)=1 \mathrm{kPa}$, and $\mathrm{T}=900^{\circ} \mathrm{C}$, and for a very thin crack opening of $2 \mu \mathrm{m}$. As the crack is quickly sealed with oxide, it was therefore more interesting to focus on the local length of consumed carbon interphase after various time durations (Fig. 6).

Indeed, as oxygen slowly diffuses within the liquid oxide, it reaches and oxidizes the carbon interphases closest to the crack entrance. After $100 \mathrm{~h}$, the interphases are attacked over the first $5 \mu \mathrm{m}$ of the material, which is not bothering since no interphase is present so close to the surface within the real material. After 1000h, the interphases are consumed over about $8 \mu \mathrm{m}$, and it is interesting to note that the consumed lengths are very high, which means that the material has no longer good mechanical capacities in this area. Indeed, over about $1 \mathrm{~mm}$ of consumed interphase at a given depth, it can be considered that all the interphase is oxidized at this depth, since the distance between two cracks is typically inferior to $1-2 \mathrm{~mm}$ (the calculated length of consumed interphase due to each crack would overlap). Finally, a calculation was performed for $20000 \mathrm{~h}$ of ageing, which is closer to the required service lives in civil aeronautics. The interphases are estimated to be completely consumed over about $14 \mu \mathrm{m}$ from the surface of the material, which represents the portion of the material having lost its mechanical properties.

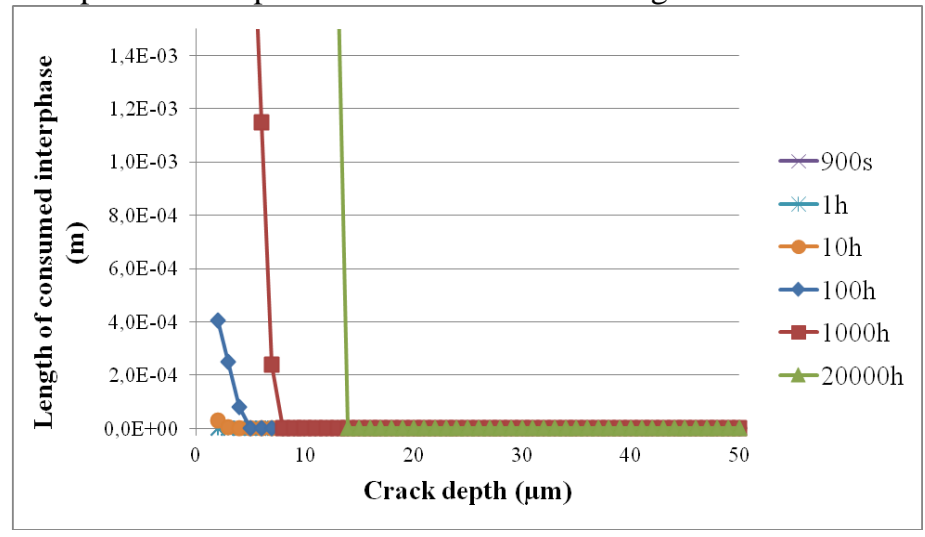

FIGURE 6. Evolution of the profile of consumed carbon interphase along a sealed $1 \mathrm{~mm}$ deep crack, crack width: $2 \mu \mathrm{m}, \mathrm{P}_{\text {tot }}=10^{5} \mathrm{~Pa}, \mathrm{P}\left(\mathrm{O}_{2}\right)=2.10^{4} \mathrm{~Pa}, \mathrm{P}\left(\mathrm{H}_{2} \mathrm{O}\right)=10^{3} \mathrm{~Pa}, \mathrm{~T}=900^{\circ} \mathrm{C}$, gas speed: $0.1 \mathrm{~m} / \mathrm{s}$ (cold zone)

This type of estimation could be very valuable to assess the lifetimes of multi-constituent materials in various environmental conditions and over very long durations. 


\section{CONCLUSION}

A model representing simultaneous oxidation and volatilization phenomena has been developed for multiconstituent self-healing materials damaged by a crack. The effects of humidity present in the environment are accurately represented, through the introduction of a delay before healing, or even, for higher water pressures, a complete impediment, leading to a recession of the crack walls. The geometries of the material and the crack are given as input and are easily adaptable. Environment conditions can be selected as well in a wide range, as long as the environmental conditions remain in the domain of definition of the overall oxidation kinetics laws. The evolution of the oxygen profile is given as one of the outputs of the model, allowing estimations of the length of consumed carbon interphase, which is critical for the material mechanical properties.

An averaged material was designed in order to get an assessment of the material behavior at larger time and space scales, with the goal of being closer to an element of an aeronautical part. Estimations of the consumed length of interphase were given as results in a typical configuration after tens of thousands of hours of exposition.

The borosilicate glass can progressively become enriched in silica with increases in time and temperature. The induced modification of the diffusion coefficient should be further taken into account, in agreement with the respective oxidation kinetics of each constituent and the dissolution of $\mathrm{SiO}_{2}$ into $\mathrm{B}_{2} \mathrm{O}_{3}$. This model is extendable to almost any multi-constituent self-healing material, and the estimations provided by the averaged version could be very valuable in the assessment of the lifetime of the material under typical aeronautical conditions. The opening of cracks can be related to various applied mechanical stresses.

\section{ACKNOWLEDGMENTS}

This work was supported by the company SAFRAN Ceramics, which contributed to provide a PhD scholarship to C. Simon.

\section{LIST OF VARIABLES}

e(z) Crack width $(\mathrm{m})$

$\delta(z) \quad$ Oxide layer thickness at the abscissa $\mathrm{z}(\mathrm{m})$

$D_{\text {eff }} \quad$ Effective diffusion coefficient $\left(\mathrm{m}^{2} \cdot \mathrm{s}^{-1}\right)$

$X_{0} \quad$ Molar fraction of oxygen

$C_{r} \quad$ Reference oxygen concentration $\left(\mathrm{mol} . \mathrm{m}^{-3}\right)$

$\mathrm{Np}_{\mathrm{i}}$ Partial order with respect to oxygen for constituent $\mathrm{i}$

$\rho_{o x} \quad$ Density of the local generated oxide $\left(\mathrm{g} \cdot \mathrm{m}^{-3}\right)$

$M_{o x}$ Molar mass of the local generated oxide(g.mol $\left.{ }^{-1}\right)$

$\mathrm{M}_{\mathrm{c}} \quad$ Carbon molar mass $\left(\mathrm{g} \cdot \mathrm{mol}^{-1}\right)$

$\rho_{\mathrm{C}} \quad$ Carbon volumetric mass $\left(\mathrm{g} \cdot \mathrm{m}^{-3}\right)$ $n_{\text {gas }} / n_{O 2}$ Ratio of the number of moles of generated gas on that of oxygen consumed

$n_{O 2} / n_{o x} \quad$ Ratio of the number of moles of oxygen consumed on that of generated oxide

$\mathrm{V}_{\mathrm{v}} \quad$ Volatilization speed $(\mathrm{mol} / \mathrm{s})$

$\mathrm{e}_{0} \quad$ Maximum width of the crack (m)

Lf Length of the crack on the outside surface (direction $y$ on Fig. 1)

$v_{\text {hot gas }}$ Gas velocity in the hot zone $(\mathrm{m} / \mathrm{s})$

$\mathrm{X}_{\mathrm{i}} \quad$ Volumetric fraction of constituent $\mathrm{i}$

$\mathrm{Kp}_{\mathrm{i}}$ Parabolic rate constant for constituent $\mathrm{i}$ $\left(\mathrm{m}^{2} \cdot \mathrm{s}^{-1}\right)$

Kc Linear rate constant for carbon oxidation $\left(\mathrm{mol} . \mathrm{m}^{-2} \cdot \mathrm{s}^{-1}\right)$

Nc Partial order regarding oxygen for carbon oxidation

Values of diffusivities of oxygen in air are taken from [15], and take into account both Fick and Knudsen diffusions. The diffusivity of oxygen in the oxide is deduced from $K_{p}$, the parabolic rate constant related to the oxide formation $\left(\mathrm{m}^{2} . \mathrm{s}^{-1}\right)$, according to Eq. 7 (as previously expressed for the $\mathrm{SiC}_{\mathrm{SiO}}$ system [8]).

$$
D_{o x}=\frac{m}{2} \frac{K_{p}}{V_{m} C_{e}}
$$


with $V_{m}$ the molar volume of the oxide $\left(\mathrm{m}^{3} \cdot \mathrm{mol}^{-1}\right), C_{e}$ the oxygen concentration within the gas environment (mol.m ${ }^{3}$ ) and $m$ the number of consumed $\mathrm{O}_{2}$ for a single generated mole of oxide.

TABLE 2. Representative kinetic values used to create the displayed figures (kinetics for a reference partial pressure of $\mathrm{O}_{2}=10^{5} \mathrm{~Pa}$ ).

\begin{tabular}{|c|c|}
\hline Kinetic parameter & Value \\
\hline Parabolic kinetic rate for $\mathrm{SiC}$ at $900^{\circ} \mathrm{C}\left(\mathrm{m}^{2} / \mathrm{s}\right)$ & $8.6 \times 10^{-20}[1,2]$ \\
\hline Partial order relative to $\mathrm{O}_{2}$ for $\mathrm{SiC}$ at $900^{\circ} \mathrm{C}$ & $0.5[1,2]$ \\
\hline Parabolic kinetic rate for $\mathrm{B}_{4} \mathrm{C}$ at $900^{\circ} \mathrm{C}\left(\mathrm{m}^{2} / \mathrm{s}\right)$ & $1.91 \times 10^{-13}[14]$ \\
\hline Partial order relative to $\mathrm{O}_{2}$ for $\mathrm{B}_{4} \mathrm{C}$ at $900^{\circ} \mathrm{C}$ & $0.5[14]$ \\
\hline Linear kinetic rate for $\mathrm{C}$ at $900^{\circ} \mathrm{C}(\mathrm{m} / \mathrm{s})$ & $1.7 \times 10^{-4}[13]$ \\
\hline Partial order relative to $\mathrm{O}_{2}$ for $\mathrm{C}$ at $900^{\circ} \mathrm{C}$ & $0.3[13]$ \\
\hline Fick diffusivity of $\mathrm{O}_{2}$ in air at $900^{\circ} \mathrm{C}\left(\mathrm{m}^{2} / \mathrm{s}\right)$ & $2.3 \times 10^{-4}[15]$ \\
\hline Diffusivity of $\mathrm{O}_{2}$ in $\mathrm{B}_{2} \mathrm{O}_{3}$ at $900^{\circ} \mathrm{C}\left(\mathrm{m}^{2} / \mathrm{s}\right)$ & $5 \times 10^{-11}[8]$ \\
\hline Linear kinetic constant $K\left(\mathrm{H}_{3} \mathrm{BO}_{3}\right)(\mathrm{m} / \mathrm{s})$ & $4.17 \times 10^{-6}[12]$ \\
\hline Activation energy $\mathrm{Ea}\left(\mathrm{H}_{3} \mathrm{BO}_{3}\right)(\mathrm{J})$ & $5530[12]$ \\
\hline Partial order relative to $\mathrm{H}_{2} \mathrm{ON}\left(\mathrm{H}_{3} \mathrm{BO}_{3}\right)$ & $1.5[12]$ \\
\hline Linear kinetic constant $K\left(H_{3} B_{3} O_{6}\right)(\mathrm{m} / \mathrm{s})$ & $2.02 \times 10^{-6}[12]$ \\
\hline Activation energy $\mathrm{Ea}\left(\mathrm{H}_{3} \mathrm{~B}_{3} \mathrm{O}_{6}\right)(\mathrm{J})$ & 37910 [12] \\
\hline Partial order relative to $\mathrm{H}_{2} \mathrm{O} \mathrm{N}\left(\mathrm{H}_{3} B_{3} \mathrm{O}_{6}\right)$ & $1.5[12]$ \\
\hline Linear kinetic constant $\mathrm{K}\left(\mathrm{HBO}_{2}\right)(\mathrm{m} / \mathrm{s})$ & $1.82 \times 10^{7}[12]$ \\
\hline Activation energy $\mathrm{Ea}\left(\mathrm{HBO}_{2}\right)(\mathrm{J})$ & $-176350[12]$ \\
\hline Partial order relative to $\mathrm{H}_{2} \mathrm{ON}\left(\mathrm{HBO}_{2}\right)$ & $0.5[12]$ \\
\hline
\end{tabular}

\section{REFERENCES}

1. L. Fillipuzzi, R. Naslain, Journal of the American Ceramic Society 77 [2], 467-80 (1994).

2. F. Lamouroux, R. Naslain, J. Jouin, Journal of the American Ceramic Society 77 [8], 2058-68 (1994).

3. N. S. Jacobson, G.N. Morscher, D. R. Bryant, R. E. Tressler, Journal of the American Ceramic Society 82 [6] 1473-82 (1999).

4. A. G. Evans, F. W. Zok, R. M. McMeeking, Z. Z. Du, Journal of the American Ceramic Society 79 [9] 2345-52 (1996).

5. W. Xu, F. W. Zok, R. M. McMeeking, Journal of the American Ceramic Society 97 [11] 3676-3683 (2014).

6. F. Rebillat, "Modélisation de la progression de l'oxydation dans des composites modèles à matrice céramique auto-cicatrisante", Matériaux 2006 Conference Proceedings, Société de Chimie Industrielle, $\mathrm{n}^{\circ} 0625,2006$.

7. L. Casas and J.M. Martinez-Esnaola, Acta Materialia 51, 3745-57 (2003).

8. B. E. Deal, A.S. Grove, Journal of Applied Physic 36, 3770-78 (1965).

9. E. Garitte, "Etude de l'oxydation/corrosion des composites céramiques", PhD Thesis, Université Bordeaux $1, n^{\circ} 3484,2007$.

10. E.F. Riebling, Journal of the American Ceramic Society 47 [10] 478-483 (1964).

11. C. S. Tedmon, Journal of the Electrochemical Society, 766 (1966).

12. G. Eriksson, K. Hack, Metallurgical Transactions B, 21B, 1013 (1990).

13. I. W. Smith, Fuel 57, 409 (1978).

14. F. Rebillat, X. Martin, E. Garitte, A. Guette, Ceramic Transactions, 215, 151-66 (2010).

15. E. N. Fuller, G. C. Giddings, Ind. Eng. Chem., 58 [5] 18-27 (1966). 